\title{
A memória social da CAPOEIRA: História e NARRATIVAS
}

Marcelo Cardoso da COSTA* Sergio Luiz Pereira da SILVA**

RESUMO: O tema proposto por este artigo é a memória social da capoeira e a sua presença na região da Baixada Fluminense-RJ. Seu objetivo é entender as seguintes questões: (i) o contexto da migração da capoeira para esta região; (ii) o surgimento da capoeira na Baixada Fluminense e; (iii) os lugares que a capoeira ocupou e vem ocupando. Para isso ele considera que a capoeira esteve presente em importantes momentos históricos do país, no entanto, na relação de poder entre o dominante e dominado, ela foi perseguida e proibida. Essa tentativa de exclusão social deixou rastros e vestígios que, através de pesquisas acadêmicas, arquivistas e etnográficas, vêm construindo a memória da capoeira em diversas localidades. Esse é o caso da presença da capoeira na região da Baixada Fluminense-RJ que, através da memória dos seus mestres, vem ganhando visibilidade.

PALAVRAS-CHAVE: Memória Social. Capoeira. Baixada Fluminense.

\section{Introdução}

A memória social da capoeira e a sua presença na região da Baixada Fluminense é o tema deste artigo.

No início do século XXI o universo da capoeira é visto como vasto e cheio de possibilidades de ser pesquisado, abrangendo diferentes olhares de campos do saber. Seu conceito é uma "teia" de sentidos e aplicações e sua manifestação cultural é caracterizada pela sua multidimensionalidade (BRASIL, 2007, p.11).

\footnotetext{
* PPGMS/UNIRIO - Doutorando do Programa de Pós-Graduação em Memória Social da Universidade Federal do Estado do Rio de Janeiro. Professor do Instituto Federal do Rio de Janeiro (IFRJ). Rio de Janeiro -RJ - Brasil. 22743-670 - marcelosociologo@yahoo.com.br. https://orcid.org/0000-0002-5833-7488.

** UNIRIO - Universidade Federal do Estado do Rio de Janeiro. Professor Associado III do Programa de Pósgraduação em Memória Social (PPGMS/UNIRIO) e da Faculdade de Ciências Sociais ((FCS/UNIRIO). Rio de Janeiro - RJ - Brasil. 22231-130 - slps2@uol.com.br. https://orcid.org/0000-0002-9417-4380.
} 
Uma dessas possibilidades, por exemplo, é a de pensar na capoeira como filosofia da ancestralidade e como um sistema integrado entre corpo e mente. Essa abordagem vem sendo difundida por Luiz Rufino (2018) e Luiz Rufino, Cinézio Feliciano Peçanha e Eduardo Oliveira (2018) numa perspectiva de pensamento diaspórico e enquanto diversidade de conhecimento, em confronto com a primazia da racionalidade do saber/poder do ocidente-europeu. Essa perspectiva faz uso do conhecimento do jogo, da ancestralidade, da ginga, do saber, da oralidade e da corporeidade como um instrumento relacional com o mundo. Essa forma de pensar a capoeira traz a inserção da pesquisa etnográfica ao universo do saber, buscando na oralidade e na memória dos seus praticantes a fonte desse conhecimento.

Essa multiplicidade de olhares vem sendo construída pela memória dos praticantes da capoeira, através da história oral e da observação participativa. Por outro lado, as fontes históricas têm dialogado com essas memórias, buscando conciliar o método historiográfico com a história oral. Dessa forma, tanto a história quanto a memória fazem parte do campo de lutas e de relações de poder, configurando um contínuo embate entre lembrança e esquecimento (GONDAR; DODEBEI, 2005).

A memória da capoeira no Brasil tem expressado essa luta de resistência e poder entre a construção de uma memória do dominante e a negação desta. A capoeira pode ser interpretada de várias formas, como manifestação da população negra, resistência à escravidão, desordem urbana, crime, esporte nacional e patrimônio cultural. Essas ressignificações da capoeira no tempo e no espaço vêm revelando diferentes pontos de vista sobre os momentos históricos. É o caso da capoeira na Baixada Fluminense, localidade pertencente à Região Metropolitana do Rio de Janeiro-RJ e que abrange treze municípios ${ }^{1}$, em que as memórias dos mestres da capoeira são importantes elementos de contribuição para a cultura, a identidade e a história nessa região ${ }^{2}$.

O intuito desse artigo é o de entender as seguintes questões: (i) o contexto da migração da capoeira para esta região; (ii) o surgimento da capoeira na Baixada Fluminense e; (iii) os lugares que a capoeira ocupou e vem ocupando.

A primeira parte deste trabalho apresenta uma reflexão crítica sobre o campo de pesquisa da memória social, enquanto, a segunda expressa a construção da memória da capoeira, utilizando alguns autores clássicos e contemporâneos da memória social. A terceira parte retrata a história e a presença da capoeira na Baixada Fluminense através dos relatos dos mestres de capoeira da região.

\footnotetext{
${ }^{1}$ Os municípios são os seguintes: Nova Iguaçu, Duque de Caxias, Belford Roxo, Guapimirim, Itaguaí, Japeri, Magé, Mesquita, Nilópolis, Paracambi, Queimados, São João de Meriti e Seropédica.

${ }^{2} \mathrm{~A}$ população da baixada é de 3.872 .615 habitantes (RIO DE JANEIRO, 2018).
} 


\section{Memória como campo de estudo}

Olick et al. (2011), na introdução do livro The collective memory reader fazem um apanhado abrangente sobre o campo de estudo da memória social: suas origens, história e a relação com o nacionalismo e a modernidade. Os autores demarcam dois momentos do chamado "boom da memória": o surgimento da ideia do nacionalismo, no século XIX, e a queda da utopia do progresso da modernidade no pós-guerra, final dos anos 1970. Esse segundo "boom da memória" se refletiu nos espaços analíticos, acadêmicos e literários, em meio a críticas sobre a sua adesão à indústria cultural e ao modismo. Olick et al. (2011) não concordam com essa crítica. Para eles esse segundo boom representou a consolidação do campo de investigação da memória, marcado por dois pontos importantes: (i) corrigir narrativas enganosas em termos das origens dos estudos da memória contemporânea e; (ii) consolidar o futuro do campo de estudo da memória social como importante área de investigação.

Ainda, para Olick et al. (2011), o mito da criação da memória, enquanto dimensão social, não tem sua paternidade associada a Maurice Halbwachs (2006). Antes desse pensador, a memória já era campo de investigação nos estudos de Platão, Nietzsche, Bergson e Freud. Para Barrenechea (2005), é Nietzsche, antes de Halbwachs, quem afirmava que a memória individual é inseparável da memória coletiva e que o fato de lembrar surge de necessidades comunitárias, da violência e das pressões coletivas.

Cabe ressaltar, no entanto, o mérito de Halbwachs (2006), pois foi este quem deu especial destaque ao conceito de memória social, ao mostrar que a materialidade da memória não estava no campo individual e sim coletivo. Para ele, cada memória individual é um ponto de vista sobre a memória coletiva, mudando de acordo com o lugar que este indivíduo ocupa e as relações que o mesmo mantém com o seu grupo social. Assim Halbwachs, ao publicar Les cadres sociaux de la mémoire em 1925, inaugurou um novo campo de investigação nas ciências humanas denominado de memória coletiva, contrapondo-se às interpretações psicologizantes da memória presentes à época (HALBWACHS, 2006; CORDEIRO, 2006).

$\mathrm{Na}$ obra Memória coletiva, Halbwachs (2006) destaca três dimensões pertinentes ao conceito de memória social: (i) pensar as memórias somente em termos de convenções sociais; (ii) a investigação deve ser no mundo empírico e; (iii) pensar o passado como reconstrução contínua no presente. Dessa forma, o conceito de memória social foi fundamental para se pensar nas narrativas da história oral, possibilitando a abertura de novas perspectivas de interpretação de um mesmo fato histórico.

O segundo "boom da memória" deu grande avanço para a consolidação desse campo de investigação, como atesta Olick et al. (2011), porém, convive com críticas 
sobre seus excessos e ambiguidades. Sarlo (2007), citando a avalanche de discursos em primeira pessoa, como histórias de vida, autobiografias, entrevistas, biografias e memória, questiona se essa "guinada subjetiva" seria um excesso testemunhal em primeira pessoa, carecendo de uma metodologia apropriada nas ciências humanas. Ela alerta que: "não há uma equivalência entre o direito de lembrar e a afirmação de uma verdade da lembrança". (SARLO, 2007, p.44). Fazendo uma forte crítica ao excesso da narrativa subjetiva e a sua relação com a história, ela traz importantes questionamentos, tais como: (i) a ambiguidade existente entre a memória e a história, em termos de reivindicação do passado e validade científica; (ii) a narração como capacidade de criação de uma nova temporalidade para a experiência; (iii) a questão do anacronismo no uso da memória e da história. Sarlo (2007) forneceu importantes reflexões no uso da memória como objeto de análise, principalmente em termos de construção de uma metodologia que tenha validade científica.

Os estudos interdisciplinares em memória social ganharam, mais tarde, importantes contribuições no livro $O$ que é memória social? organizado por Gondar e Dodebei (2005). Seus dez artigos “[...] delineiam os contornos problemáticos do campo social e da memória, trabalhando para a construção de conceitos que lhe correspondam" (GONDAR; DODEBEI, 2005, p.9-10). Em outro trabalho, Cinco proposições sobre memória social, Gondar (2016) busca demarcar o campo da memória social nos seguintes pontos: (i) é transdisciplinar; (ii) é ético e político; (iii) implica o esquecimento; (iv) não se reduz a identidade e; (v) não se reduz a representação.

Ao pesquisar a capoeira na Baixada Fluminense percebe-se que, por um lado, havia uma lacuna na historiografia acadêmica e, por outro lado, boa parte da história e da cultura dessa prática está presente na memória dos seus praticantes. A partir dessas constatações surgiram as questões: como trabalhar esses relatos? Como levar isso para o campo científico e que metodologia aplicar?

Foi no campo de investigação teórico e metodológico da memória social que encontramos abrigo para trabalhar essas questões. Os conceitos de memória coletiva em Halbwachs (2006), de história em Michel Foucault (1989) e Walter Benjamin (1985) e de rastros em Jeanne Gagnebin (2012), foram as principais referências teóricas. Pensar a prática da capoeira, por essa perspectiva, é fazer surgir os vestígios e rastros históricos da sua presença, desvendando sua relação de poder e o contexto social de suas manifestações ao longo do tempo e do espaço.

Ao trabalhar com as memórias dos mestres e praticantes de capoeira duas imagens são frequentes: a da capoeira enquanto prática criminalizada - fruto de preconceitos e de perseguições, e a da luta pelo seu reconhecimento enquanto valor cultural e histórico (ABREU e CASTRO, 2009; COSTA e RANGEL, 2010). Essas duas 
imagens fazem parte da abordagem histórica sobre acontecimentos do passado e do presente e nos remete à relação existente entres os conceitos de memória e de história. Ambos os conceitos lidam com o passado através do presente e são historicamente datados, surgidos na sociedade grega clássica, porém sendo diferentes em seus significados.

Foi na sociedade capitalista moderna, segundo Benjamin (1985), que a história foi aprisionada no conceito de ciência, afastando-se do campo das artes e da filosofia e, ao mesmo tempo, se transformando no discurso oficial dos vencedores. Isso fez com que a memória deixasse de ser encarada como um conhecimento para ser apenas uma abordagem do campo historiográfico.

Fustel de Coulanges recomenda ao historiador interessado em ressuscitar uma época, que esqueça tudo o que sabe sobre fases posteriores da história. Impossível caracterizar melhor o método com o qual rompeu o materialismo histórico. Esse método é o da empatia. Sua origem é a inércia do coração, a acedia, que desespera de apropriar-se da verdadeira imagem histórica, em seu relampejar fugaz. Para os teólogos medievais, a acedia era o primeiro fundamento da tristeza. [...] A natureza dessa tristeza se tornará mais clara se nos perguntarmos com quem o investigador historicista estabelece uma relação de empatia. A resposta é inequívoca: com o vencedor. Ora, os que num momento dado dominam são os herdeiros de todos os que venceram antes. A empatia com o vencedor beneficia sempre, portanto, esses dominadores (BENJAMIN, 1985, p.225).

Benjamin (1985), ao escrever as teses Sobre o Conceito de História, faz uma crítica contundente sobre as concepções históricas defendidas pelo positivismo, pelo historicismo e pela social-democracia, que apostavam em um modelo historiográfico do progresso irresistível da história. Esse progresso da modernidade, e o investigador historicista, dizia ele, estariam comprometidos com o dominador. Segundo ele, é preciso ter em mente essa associação e dela se afastar, buscando no materialismo histórico o método de contraposição e de crítica. Assim Benjamin (1985) termina a sétima tese sugerindo que é preciso "escovar a história a contrapelo", ou seja, é preciso recusar a tradição dos vencedores e seguir o caminho dos despojos deixados pelo historicismo, que nos remeterá à empatia com a história dos vencidos, dos excluídos. O propósito era o de compreender a história do ponto de vista dos vencidos e empreender a crítica da modernidade capitalista.

A nona tese sobre o conceito de história, traz a imagem do "Anjo da história" que: 
[...] gostaria de deter-se para acordar os mortos e juntar os fragmentos. Mas uma tempestade sopra do paraíso e prende-se em suas asas com tanta força que ele não pode mais fechá-las. Essa tempestade o impele irresistivelmente para o futuro, ao qual ele vira as costas, enquanto o amontoado de ruínas cresce até o céu. Essa tempestade é o que chamamos progresso. (BENJAMIN, 1985, p.226).

Esse "Anjo da história" está sendo aprisionado pelo progresso, construído sobre catástrofes, massacres e violências infligidas aos vencidos no decorrer da história. Para libertá-lo se faz necessário fazer a seguinte tarefa: resgatar a memória histórica dos dominados, seus pensamentos, personagens e eventos e, ainda, empreender a crítica sobre ideia de progresso.

Foucault (1989), influenciado pela filosofia histórica de Nietzsche ${ }^{3}$, elabora o método da genealogia, que é uma técnica de investigação preocupada com o contexto das relações de força e não em descobrir as origens das ideias, valores ou identidades sociais. Nessa concepção, a verdade histórica é dada e forjada pelas relações de força de cada época. A uniformidade e regularidade da história são negadas, existindo a irregularidade e a inconstância. Isso faz com que a história não tenha uma ordem linear. Essa perspectiva histórica é reveladora dos discursos e dos micro-poderes presentes na definição de exclusão de grupos ou classes sociais, revelando a constituição de forças políticas dominantes que, em cada época, impõem sua verdade e silencia a cultura dos que foram dominados. É nesse contexto de poder que foi possível, por exemplo, a criação da identidade nacional, operando numa lógica dialética entre incluídos e excluídos, quando da imposição pelo uso da força dos Estados Nacionais sobre as regiões contrárias a essa centralização do poder - período do fim do século XVIII ao início do século XIX.

As análises de Benjamin (1985) e Foucault (1989) sobre a história ajudam a investigar os rastros e vestígios de memórias que foram ocultadas, buscando vestígios do passado nas diversas camadas do presente. Seguindo esse pensamento, Gagnebin (2012) destaca a importância desses rastros e vestígios para o campo da memória, dizendo que:

Na tradição filosófica e historiográfica, o conceito de "rastro" é caracterizado por sua complexidade paradoxal: presença de uma ausência e ausência de uma presença, o rastro somente existe em razão de sua fragilidade. Ele é rastro porque

\footnotetext{
${ }^{3}$ Nietzsche propôs o uso de uma filosofia histórica para analisar os valores e a moralidade da sociedade moderna através do poder. Esse método visava unir sem subordinar a filosofia à história.
} 
sempre ameaçado de ser apagado ou de não ser mais reconhecido como signo de algo que assinala (GAGNEBIN, 2012, p. 28).

Os rastros indicam a procura do ausente da história oficial e revela vestígios do passado nas camadas do presente. No entanto, por outro lado, expressa também a tentativa de apagamento da memória. $\mathrm{O}$ rastro é fruto do acaso, sem intencional idade, porém, se assim o é, também é não-intencional o seu decifrar. Esses rastros não são criados, como os demais signos culturais e linguísticos, mas sim, deixados ou esquecidos (GAGNEBIN, 2012). Para Gagnebin (2012, p.33), a leitura de Benjamin sobre a história é: "procurar por rastros deixados pelos ausentes da história oficial [...] e, também, por rastros de outras possibilidades de interpretação de uma imagem imutável dos acontecimentos e das obras do passado".

Esse desvendamento dos rastros e vestígios da história representa a luta contra o processo de apagamentos, ocultações e sumiços. Além disso, ao ser decifrado, contribui para trazer novos elementos sobre a história.

Relacionando as teorias sobre a história de Benjamin (1985) e Foucault (1989) e as ideias de rastros, vestígios e apagamento com a pesquisa sobre a capoeira têm-se que: em vez de se pensar na identidade relacionada à capoeira ou mesmo a um mito de origem, convêm pensar no contexto de seu surgimento, criminalização e aceitação atrelada às relações de poder no conjunto da rede social (FOUCAULT, 1995). Nessa perspectiva pode-se afirmar que: a capoeira é fruto do poder do comércio de escravos, da lógica capitalista do colonialismo e da violência da diáspora africana. Passou por processos de perseguição e tentativa de apagamento da sua memória e, segundo a concepção foucaultiana, por um movimento de contra-memória, contrário a imposição da memória do colonizador.

Foucault (1989) utiliza o termo de contra-memória para pensar a escrita da história. Enquanto a perspectiva tradicional de construção da história segue um continuum lógico de acontecimentos e registro linear de pessoas, dando a conhecer a memória coletiva que o tempo preservou, a genealogia foucaultiana concentra-se nas descontinuidades e nas rupturas que a história também guarda. Essa última realça as diferenças entre as consciências coletivas, não ignorando os temas mais marginais como a sexualidade e a loucura, que desafiam qualquer tentativa de interpretação da história como um continuum de identidades mais ou menos unificadas. Nessa contra-memória, a resistência à escravidão, a valorização das lembranças africanas e a sobrevivência das manifestações culturais negras expressaram a reação ao esquecimento. A prática da capoeira pode aqui ser pensada dentro dessa lógica, desafiando, como diz Foucault 
(1989), qualquer tentativa de interpretação da história como um continuum de identidades mais ou menos unificadas.

As pesquisas sobre o passado escravista no Brasil, de acordo com a historiadora Mary Karasch (2000) encontram seu limitador nas poucas fontes da elite sobre o detalhamento de informações sobre a vida e a cultura dos escravos. Isso se reflete na pouca, ou nenhuma abordagem jornalística da época, "exceto quando continham debates sobre a abolição do tráfico de escravos, ou traziam anúncios de compra e venda de escravos, ou noticiavam um crime sensacional envolvendo um cativo" (KARASCH, 2000, p.20). Karasch (2000) constatou isso, quando da sua pesquisa sobre a vida dos escravos no Rio de Janeiro do começo do século XIX. Outro limitador foi o fato de a escravidão ser vista como natural por parte da elite brasileira e, também, dos historiadores que escreviam e pesquisavam sobre os feitos e acontecimentos da corte brasileira e seus costumes, ignorando a massa de escravos existentes. Foi utilizando a metáfora do arqueólogo que Karasch (2000) seguiu os rastros e descobriu na visão dos estrangeiros as fontes que perseguia.

O trabalho de Mary Karasch (2000), junto ao trabalho de Thomas Holloway (1997), Polícia no Rio de Janeiro: repressão e resistência numa cidade do século XIX, abriram caminho para inúmeros trabalhos de pesquisa e se tornaram referências sobre a escravidão para diversos pesquisadores. Foi o caso do historiador Carlos Eugênio Soares que elaborou dois importantes trabalhos que resgataram a capoeira do esquecimento e da história. São eles: A Negregada Instituição: os capoeiras na Corte Imperial (18081850) (1999) e A capoeira escrava no Rio de Janeiro 1808-1850 (2004).

Esses trabalhos, ajudaram a tirar a capoeira dos "pés de página da historiografia" (OLIVEIRA; LEAL, 2009, p.40). Além disso, contribuíram para a abertura do espaço na academia para essa temática.

\section{História, memória e capoeira}

A trajetória histórica da capoeira foi sendo construída e reinventada ao longo dos tempos, de acordo com o contato com o outro, com o diferente e precisou incorporar novos valores e ressignificação de espaços e ritos para continuar a existir. A capoeira esteve presente nas descontinuidades e nas rupturas que a história também guarda, o que torna difícil qualquer tentativa de interpretação. Destacamos quatro momentos históricos em que a capoeira pode ser pesquisada e analisada como memória coletiva, em sua relação com o poder existente e visão relacional entre o lembrar e o esquecer. 
No primeiro momento, no período 1808 a 1850, existiu a capoeira escrava (BRASIL, 2007). A capoeira aqui não se restringia a "uma prática cultural excludente de negros libertos ou livres e sim, também, relacionada a uma tradição rebelde que tinha fortes raízes escravas" (SOARES, 2004, p.25). A relação de poder nesse período é dada pelo sistema de colonização escravista, em que o dominado impõe seu poder e sua verdade baseada na lógica colonizadora. Nesse contexto a capoeira aparece nas festividades urbanas, nos portos, no espaço público e como forma de resistência à escravidão.

Para Mestre Warle ${ }^{4}$, a capoeira estava associada ao processo de escravidão e a formação da comunidade quilombola, expressa nas suas danças, crenças, valores, lutas e jogos, como a capoeira.

A história da capoeira está intimamente ligada a Baixada Fluminense. A área da Baixada Fluminense possuía muitos quilombos e senzalas, destacando a fazenda São Bernardino ${ }^{5}$, na região de Vila de Cava (atual distrito de Nova Iguaçu) que possuía cemitério de escravos, senzalas, quilombos. (COSTA, 2018, p.83).

Essa informação aparece na história oral dos mestres de capoeira, porém, seus rastros ainda estão por ser seguidos e pesquisados pela história, principalmente em relação à região da Baixada Fluminense.

Em um segundo momento a capoeira é vista como classe perigosa e como crime. Soares (2004) identifica esse momento no período que vai de 1850 a 1890, caracterizado por uma grande população negra na cidade do Rio de Janeiro (BRASIL, 2007). A capoeira, nesse momento, deixa de ser composta somente pela população negra e passa a incorporar boa parte das classes populares que não estavam inseridas dentro das relações de poder dominante. Os praticantes de capoeira passaram a utilizar estratégias de uso e controle dos espaços urbanos, de oferta de segurança e de proteção política. Surgiram grupos que controlavam parte dos espaços urbanos e que eram denominados de Maltas, visto como criminosos. Por outro lado, a oferta de segurança privada de políticos e partidos, a luta na Guerra do Paraguai (1864-1870) e a formação da Guarda Negra (1888) foram tentativas de inserção social. Por ser organizada em Maltas a capoeira estava associada ao termo de vadiagem, ao crime e a grupos de desordeiros, o

\footnotetext{
${ }^{4}$ Warle Silva de Paula (Mestre Warle) nasceu 1935 e foi formado pelo mestre Medeiros.

${ }^{5}$ A Fazenda São Bernardino foi construída em 1875 pelo português Bernardino José de Souza e Melo. Tombada pelo Patrimônio Histórico em 1951, contava com cavalariças, garagem para carruagens, senzalas, habitações para escravos e engenhos de cana e mandioca. Foi destruída por um incêndio na década de 1980.
} 
que fez com que ela ficasse na clandestinidade e fosse tratada, pelas autoridades públicas, como algo a ser exterminado.

A capoeira já era combatida na época do Império, contudo foi no começo da República que ela foi criminalizada no código penal brasileiro pelo Decreto número 847, de 11 de outubro de 1890 (BRASIL, 1890), passando seus praticantes a serem perseguidos, presos e deportados, acusados de vadiagem.

Capítulo XIII - Dos vadios e capoeiras

Art. 402. Fazer nas ruas e praças públicas exercício de agilidade e destreza corporal conhecida pela denominação Capoeiragem: andar em carreiras, com armas ou instrumentos capazes de produzir lesão corporal, provocando tumulto ou desordens, ameaçando pessoa certa ou incerta, ou incutindo temor de algum mal; Pena de prisão celular de dois a seis meses.

A penalidade é a do art. 96.

Parágrafo único. É considerado circunstância agravante pertencer o capoeira a alguma banda ou malta. Aos chefes ou cabeças, se imporá a pena em dobro.

Art. 403. No caso de reincidência será aplicada ao capoeira, no grau máximo, a pena do art. 400. Com a pena de um a três anos.

Parágrafo único. Se for estrangeiro, será deportado depois de cumprida a pena.

Art. 404. Se nesses exercícios de capoeiragem perpetrar homicídio, praticar alguma lesão corporal, ultrajar o pudor público e particular, perturbar a ordem, a tranquilidade ou segurança pública ou for encontrado com armas, incorrerá cumulativamente nas penas cominadas para tais crimes. (BRASIL, 1890, n.p.).

Esse código fez a capoeira ser proibida por lei no período de 1890 a 1937. Ela não fazia parte da construção de identidade que a república tentava forjar, que era a de um nacionalismo nos moldes europeu. Esse nacionalismo republicano buscou esquecer o passado colonial e escravista, as manifestações da cultura negra e combater os inimigos da república. A capoeira, nesse sentido, era inimiga, pois apoiou o Império contra a república ${ }^{6}$. Esse episódio quase representou o fim da cultura da capoeira.

No terceiro momento, a capoeira é vista e associada ao esporte nacional (BRASIL, 2007, OLIVEIRA; LEAL, 2009). Ajudada por alguns intelectuais, a capoeira buscou ser encaixada dentro da identidade nacionalista que estava sendo construída pelo governo populista de Getúlio Vargas (1934-1937). Com a ideia de que a capoeira

\footnotetext{
${ }^{6}$ Muitos capoeiristas faziam parte da Guarda Negra da Redentora, formado por um grupo de ex-escravos logo após a assinatura da Lei Áurea, pela Princesa Isabel, em 1888. Eram abolicionistas e monarquistas e, em suas ações, buscavam dispersar manifestações republicanas, usando a força e a o jogo da capoeira.
} 
representava a legítima luta e esporte nacional, buscou-se a ressignificação da capoeira dentro do contexto nacional populista do governo Vargas.

Coelho Neto representou o ponto alto da versão que defendia a transformação da capoeira em esporte nacional. [...] Coelho Neto não apenas realça as qualidades ginásticas da capoeira. Ele a celebra como verdadeira educação física do Brasil, que deve ser ensinadas nas escolas, quartéis, lares, em quaisquer lugares onde a instrução seja importante. (SOARES, 2004, p.40 e 12).

Foi nesse contexto que Mestre Bimba (1900-1974) criou na Bahia, em 1932, a primeira academia especializada em capoeira: a Luta Regional Baiana ou apenas Capoeira Regional. Bimba sistematizou os golpes, criou um método de ensino e fundou assim a primeira escola de capoeira. Esse fato buscava modificar a imagem da capoeira ligada ao processo de escravidão, ao da vadiagem e aos desocupados, tirando-a da criminalidade e fazendo com que se aproximasse da luta e do esporte. Com isso, criouse uma nova tradição da capoeira (BRASIL, 2007, p.37). Esse movimento fez com que a capoeira passasse a ser aceita em suas práticas e fazeres.

Ao sistematizar os golpes e incorporar atributos de outras artes marciais, a capoeira Regional sofreu críticas de alguns capoeiristas, que reagiram criando uma outra escola de capoeira. Foi aí que entrou em cena Mestre Pastinha (1889-1981), criador do Centro Esportivo de Capoeira Angola (CECA), em 1941. Essa escola ficou conhecida como Capoeira Angola, que tem uma narrativa de resgate da capoeira ligada à cultura africana e ao período da escravidão.

No quarto momento a capoeira é globalizada e reconhecida como patrimônio cultural. Demarcado pela inauguração da primeira escola de capoeira angola dos Estados Unidos em 1990, quando passa a ser vista como elemento pertencente à cultura e à história afro-brasileira, inserida na Lei 10.639/03 que inclui no currículo oficial da rede de ensino a temática História e Cultura Afro-Brasileira. É nesse contexto que, mais adiante, vai surgir o movimento de patrimonialização dos elementos da cultura afrobrasileira, como as religiões de matrizes africanas, o samba e a capoeira. Foi assim que em 2008 a capoeira se torna Patrimônio Cultural Brasileiro pelo Instituto do Patrimônio Histórico e Artístico Nacional (IPHAN) ${ }^{7}$ e depois, em 2014, patrimônio cultural imaterial da humanidade pela Unesco, órgão vinculado à ONU.

\footnotetext{
7 O discurso de Gilberto Gil, Ministro da Cultura do Brasil, na Organização das Nações Unidas (ONU) em 2004, lançou as bases para um programa brasileiro e mundial para a capoeira, ressaltando sua expansão mundo afora e a ideia da reparação histórica a esta manifestação dos africanos escravizados no Brasil.
} 
Esses quatro momentos podem ser analisados pela relação com os conceitos de identidades e diferença que são, segundo, ativamente produzidos como criações sociais e culturais, estando em estreita conexão com a relação de poder.

A afirmação da identidade e a marcação da diferença implicam, sempre, as operações de incluir e de excluir [...] afirmar a identidade significa demarcar fronteiras, significa fazer distinções entre o que fica dentro e o que fica fora. A identidade está sempre ligada a uma forte separação entre 'nós' e eles. (SILVA, 2003, p.82).

A capoeira, como se observou, expressou a luta pela aceitação social, a preservação e a história e cultura de uma população excluída. Ela possui estreitas conexões com as relações de poder, demarcando os incluídos (europeus, colonizadores, brancos e civilizados) e os excluídos (não europeu, colonizados, não brancos e bárbaros). A memória daqueles denominados diferentes, visto como o outro, explora as possibilidades de confrontar a história do diferente, daqueles que reivindicam uma outra narrativa.

\section{A capoeira na Baixada Fluminense}

Boa parte da historiografia da capoeira no Brasil é rica em pesquisas sobre a prática da capoeira nas capitais da Bahia (Salvador), de Pernambuco (Recife) e do Rio de Janeiro (Rio de Janeiro). No entanto, atualmente vem se observando a história da sua cultura e memória em outros estados, municípios e espaços do entorno das capitais. Este é o caso da região da Baixada Fluminense no Rio de Janeiro. Muito das histórias e da cultura da capoeira está viva nas memórias dos mestres de capoeira da região.

A cultura da oralidade ficou evidente nas entrevistas com nove mestres de capoeira da Baixada Fluminense em 2010, por ocasião da produção da Revista capoeira: resistência da cultura afro-brasileira na Baixada Fluminense (COSTA; RANGEL, 2010). As questões elaboradas para as entrevistas buscavam informações sobre a trajetória dos mestres de capoeira, sua presença na Baixada e suas lembranças sobre a capoeira $^{8}$.

\footnotetext{
${ }^{8}$ Entrevistas realizadas na Casa de Cultura da Baixada, em São João de Meriti, com os seguintes mestres de capoeira: Mestre Sampaio (SAMPAIO, 2010), Mestre Canela (SOUZA, J. 2010), Mestre Portes (PORTE, 2010), Mestre Levi (SOUZA, L. 2010), Mestre Raimundo (SILVA FILHO, 2010), Mestre Rui Charuto (MONTANHEIRO, 2010), Mestre Warle (DE PAULA, 2010), Mestre Magal (JUGNÁTICO, 2010; 2013) e Mestre Reginaldo Pimentel (SANTOS, 2010).
} 
Utilizando o conceito de memória coletiva de Halbwachs (2006), percebemos que essas entrevistas somente fazem sentido em relação ao grupo do qual esses mestres de capoeira participam, pois são depoimentos de acontecimentos vividos em comum pelo grupo. O "eu” depõe e dá testemunhos para a construção da memória no presente e faz com que os rastros de memória vão surgindo, o que deixa transparecer narrativas diversas sobre determinado acontecimento histórico.

Durante as entrevistas era comum aos mestres de capoeira lembrarem e retratarem algumas fases históricas e sociais conhecidas e vivenciadas pela capoeira, bem como a chegada deles na região. Narrativas sobre sua formação como mestres, as dificuldades de viverem dessa profissão e a sua visão sobre os espaços da cidade foram sendo reveladas. As tensões atuais também se fizeram presentes, bem como suas estratégias de sobrevivência e luta para preservar essa tradição cultural na Baixada Fluminense. Foi através desse contato com os entrevistados que se percebeu que havia uma riqueza cultural e social baseada na oralidade, nas memórias e na produção cultural. Essa riqueza, no entanto, está pouco documentada e perde um pouco de seus vestígios com o falecimento de alguns membros do grupo.

Os estudos sobre a pesquisa com a história oral tornaram-se necessários nas análises do trabalho de campo. Um desses estudos é a obra de Michael Pollak (2010), A gestão do indizível, em que ele trabalha a memória como temporalidade local ao lembrar das datas e da cronologia dos fatos, relacionando história e localizações espaciais e tratando, também, do silêncio relacionado ao esquecimento na fala dos entrevistados. Ele então alerta que: "histórias e memórias devem ser relacionadas aos locais onde elas foram produzidas, assim como aos públicos aos quais elas se destinam. Tal análise do relato de vida deve ser considerada como uma reconstrução da identidade e não apenas como uma narrativa factual" (POLLAK, 2010, p.9).

O recorte sobre o tempo, período histórico da chegada dos mestres a região, o espaço, localidades de suas atividades e a criação cultural de sua arte foram importantes para a reconstrução da identidade da capoeira.

Essa materialidade das memórias lança luz sobre os rastros e vestígios da história e da cultura existente na Baixada Fluminense. O intuito é o de libertar o "Anjo da História" Benjaminiano. Abreu e Castro (2009) seguiram esse caminho. No livro Capoeira, eles trabalharam a história oral da capoeira em vinte e seis entrevistas de mestres de capoeira, na qual aparecem narrativas de novas visões da história, descobrindo e valorizando personagens até então ocultos e acontecimentos que fizeram com que fossem possíveis o desenvolvimento da capoeira e o reconhecimento de sua importância para a história. 
Em uma das entrevistas, no trabalho de campo que realizamos, foi apresentado um diagrama contendo a árvore genealógica de ramificação dos mestres de capoeira (COSTA; RANGEL, 2010). Esse material representa a genealogia da capoeira da Baixada Fluminense e expressa a lógica de organização e da memória coletiva, na qual o pertencimento a uma linhagem é uma forma de demarcar e construir as identidades associadas a estilos de capoeira diferentes e a seus fundadores. Essa identidade pode ser pensada em termos de sua história, tempo e espaço, representando uma referência de status, honra, prestígio e preservação da memória através de imagens e narrativas.

Boa parte desses mestres de capoeira tem seu histórico de chegada a Baixada Fluminense na segunda metade do século XX, década de 1960 e 1970. Essa migração ocorreu por dois motivos. O primeiro se refere ao fenômeno das reformas urbanas na cidade carioca, em que a lógica do ordenamento do espaço urbano era o da expulsão das classes populares e de suas práticas culturais indesejadas. $\mathrm{O}$ intuito era o de impor a lógica civilizatória burguesa da modernidade. Todavia, como num gingado do corpo no jogo da capoeira, houve um movimento de resistência, migração e reprodução da capoeira em outras localidades. O segundo motivo foi o barateamento das moradias e terrenos na Baixada Fluminense. Essa região estava passando por um intenso processo de expansão de seus loteamentos, pertencentes a antigas fazendas, e recebendo grande contingente populacional.

A capoeira carioca, nesse período, migra para os morros, subúrbios e outras regiões, como a Baixada Fluminense. No entanto, desenvolve-se um intenso intercâmbio entre capoeiristas que migraram para essas localidades e, principalmente, com a capoeira carioca. Mestre Rui Charuto ${ }^{9}$ relata que o contato entre os capoeiristas da Baixada Fluminense com os do Rio de Janeiro era constante, onde os primeiros aprendiam as técnicas, a organização e a maneira de ensino com os capoeiristas da capital carioca.

$\mathrm{Na}$ época dos escravos, quando se falava em roda de capoeira, era porque ela era itinerante e "rodava" nos terreiros dos mestres. O Rio de Janeiro foi o ponto de partida e de referência dessas rodas. Havia, por exemplo, a famosa roda de Zé Pedro (no Rio de Janeiro), que era frequentada pelos mestres Valdir Sales, Barbosa, Gavião e Paulo Gomes. Esse pessoal participava dessa roda e depois convidavam os outros mestres para participarem das rodas que aconteciam na Baixada Fluminense, em Duque de Caxias, Belford Roxo e São João de Meriti (COSTA, 2018, p.84).

\footnotetext{
${ }^{9}$ Rui Montanheiro (Mestre Rui Charuto) começou na capoeira em 1966 no Rio de Janeiro, no bairro de Pilares.
} 
Essa referência, localização e história ajudam a seguir os rastros e vestígios da capoeira na Baixada, trazendo à tona: manifestações culturais e históricas, contexto social em que vivem e a memória do passado e do vivido. Os depoimentos, através das entrevistas, concordam no essencial apesar de divergirem em alguns pontos. É esse essencial que nos permite reconstruir um conjunto de lembranças de modo a reconhecêlo. Dessa forma, nomes, lugares e histórias do grupo foram sendo socializados.

Mestre Levi ${ }^{10}$ fala sobre a localização e os mestres precursores mais importantes da capoeira na Baixada Fluminense:

A capoeira começa no início da década de 1960, por volta de 1962, através do mestre Paulo Gomes, que veio do Rio de Janeiro para o bairro de Coelho da Rocha (rua Belkiss) em São João de Meriti. A capoeira tem uma rede de formação que expressa uma linhagem dos mestres formados e formadores. Dessa forma, situase o mestre Paulo Gomes como aprendiz de Artur Emídio (que foi aprendiz de Paizinho) e formador dos mestres Josias da Silva e Valdir Sales. O mestre Josias da Silva formou os mestres Canela, Raimundo, Butt, Crispin e Irani. Já o mestre Valdir Sales formou os mestres Medeiros, Barbosa, Portes, Ninguém, Morais, Baianinho, Tião, Sabatine, Claudir, Décio. (COSTA, 2018, p.85).

Foi através desse intercâmbio entre os capoeiristas que mestre Paulo Gomes ${ }^{11}$, baiano de Itabuna, veio morar em São João de Meriti, no bairro de Coelho da Rocha, na década de 1960. Paulo Gomes trouxe para a Baixada Fluminense a capoeira que aprendia com mestre Arthur Emídio, formando outros mestres que a intensificaram na região, principalmente em São João de Meriti, caso de mestre Valdir Sales, que criou a Associação de Capoeira Valdir Sales, e mestre Josias da Silva, que criou a Associação de Capoeira Josias da Silva, difundindo-a nos municípios de Nova Iguaçu e Duque de Caxias.

Mestre Reginaldo Pimentel, no entanto, relata outra possível trajetória da capoeira na Baixada Fluminense. Nesta, há uma ligação direta com a capoeira baiana de Mestre Pastinha.

Eu cheguei a Baixada Fluminense vindo de Salvador na década de 70 e comecei a procurar saber aonde se jogava a capoeira. Em Nilópolis e Nova Iguaçu eu não encontrei nenhuma roda de capoeira. Em São João de Meriti sabia que tinha a

\footnotetext{
10 Levi Tavares Souza (Mestre Levi) foi formado pelo mestre Khovo.

11 Paulo Gomes da Cruz, o mestre Paulo Gomes (1941-1998) é considerado o principal fundador e difusor da capoeira na Baixada Fluminense.
} 
capoeira do mestre Valdir Sales e em Duque de Caxias do mestre Barbosa e só. Eu me considero o fundador da capoeira em Anchieta, Nilópolis e Nova Iguaçu. A capoeira que eu praticava era a capoeira baiana do meu mestre Pastinha. Eu tinha um diploma dado por ele que provava que eu já dava aula em Salvador. No Rio de Janeiro não me filiei a nenhuma academia, pois quis ser fiel a escola do meu mestre formador. A primeira academia que dei aula foi em Nilópolis. Dava aulas também no bairro de Anchieta (município do Rio de Janeiro) no "E.C. Royal" (localizado em frente à atual escola Paraíba e que hoje é uma Igreja Evangélica) e no "E.C. Anchieta". Dei aula também no $6^{\circ}$ batalhão de polícia militar de Duque de Caxias e na escola de formação de oficiais. (COSTA, 2018, p.87).

Nas entrevistas que realizamos apareceram algumas tensões sobre a origem de alguns mestres de capoeira e, também, sobre a própria origem da capoeira: se ela é carioca ou baiana. Por outro lado, houve consenso sobre o nome do mestre Paulo Gomes como o principal articulador da capoeira na Baixada Fluminense.

\section{A Roda de capoeira de Caxias}

Em dois trabalhos de pesquisa etnográfica sobre o desenvolvimento da capoeira em Duque de Caxias, encontramos nomes e referências ligados ao Mestre Paulo Gomes, ao intercâmbio com a capoeira carioca e a migração da capoeira para a Baixada Fluminense (MARQUES; FILHO, 2011, ALMEIDA; BARTHOLO; SOARES, 2013). Isso confirma o que já se disse anteriormente: a capoeira que chega à região é fruto da migração de seus praticantes e do intenso intercâmbio com a capoeira carioca.

Marques e Filho (2011), no artigo A trajetória da capoeira em Caxias, fazem uma análise histórica do surgimento da capoeira no município de Duque de Caxias.

Antes da década de 60 não encontramos registros sobre a presença real de capoeiristas na cidade. No campo literário fomos apresentados ao Negro Sabará, personagem da trilogia publicada por Santos Lemos. Após consultarmos os vários praticantes da capoeira na cidade encontramos Mestre Barbosa, Mestre Gegê, Mestre Raymundo Filho, Mestre Levi, Mestre Monge e Mestre Russo entre os seus mais antigos praticantes. (MARQUES; FILHO, 2011, p.79).

Nesse trabalho etnográfico, feito a partir da entrevista com oito mestres de capoeira, aparecem nomes, academias e rodas de capoeira. 
No artigo Uma roda de rua: notas etnográficas da roda de capoeira em Caxias, Almeida, Bartholo e Soares (2013) apresentam uma pesquisa sobre a história e a cultura da "Roda de Caxias", entrevistando seus frequentadores.

Esses dois artigos foram importantes para que pudesse ser materializada, através da memória dos entrevistados, a presença da capoeira em Duque de Caxias: seu surgimento, trajetória e situação atual.

Outra memória de referência da capoeira na Baixada Fluminense foi o processo de formação da roda de capoeira de Duque de Caxias, nascida na época do regime militar, década de 1970.

Os trabalhos etnográficos de Marques e Filho (2011) e Almeida, Bartholo e Soares (2013), descrevem a trajetória, as tensões e narrativas sobre a "Roda de Caxias" e desvendam os rastros e vestígios da presença da capoeira no município de Duque de Caxias. Ambos coletaram informações fazendo pesquisa de campo.

Almeida, Bartholo e Soares (2013) aplicaram questionários e entrevistaram os frequentadores, além de fazer a observação participante da roda. Através das narrativas de capoeiristas frequentadores da roda, eles obtiveram importantes informações que ajudam a pensar a prática e o ensino da capoeira na Baixada Fluminense.

O município de Duque de Caxias, localizado no Estado do Rio de Janeiro, Brasil, apesar de não ser identificado "no mapa cultural" da incipiente historiografia da capoeira como um local que auxiliou a formar tradição dessa prática corporal, teve suas ruas e praças como palco do nascimento e manutenção de uma roda de capoeira de rua que se mantém há mais de trinta anos. (ALMEIDA; BARTHOLO; SOARES, 2013, p.125).

A "Roda de Caxias" expressou as tensões existentes entre seus praticantes e o poder político e, também, entre capoeiristas de escolas de capoeira regional e angola. $\mathrm{O}$ cenário político do seu surgimento foi assim descrito:

$\mathrm{Na}$ década em que os primeiros capoeiristas se instalaram em Duque de Caxias esta cidade se tornou Área de Segurança Nacional e, a partir de 1971, seus prefeitos eram militares interventores que cerceavam ainda mais, a liberdade da população de Duque de Caxias. As manifestações populares sofreram rígido controle. Entre elas a capoeira. Este cerceamento relacionava-se a uma prática política a nível nacional. (MARQUES; FILHO 2011, p.82).

A formação de grupos de capoeiras em escolas, associações e academias foi incentivada a partir de década de 1970, mas a sua prática em locais públicos, como ruas 
e praças, não era bem-vista e sofria com as ações dos órgãos de repressão. Relatos de conflitos, prisões, mudança de locais e resistência acompanharam a história da roda. Já, a tensão que provocou entre os capoeiristas se deu devido ao conflito de um grupo com a então capoeira esportiva e acadêmica, baseada no estilo da capoeira regional.

A Roda de Caxias surge da ruptura de um grupo de jovens praticantes do sistema que aqui chamaremos de capoeira esportiva. A capoeira praticada em academias de ginástica é nomeada, por alguns antigos freqüentadores da roda na linguagem nativa, como sistema acadêmico, aqui identificado de capoeira esportiva. Esse modelo parece ter uma estrutura semelhante às das artes marciais orientais, com uniformes, graduações e hierarquia, utilizando treinamento e disciplina esportiva. (ALMEIDA; BARTHOLO; SOARES, 2003, p.125).

Foi contra a lógica de ação da capoeira regional, da criação de regras de institucionalização da capoeira e, também, contra a saída da capoeira dos espaços públicos para o espaço privativo das academias, que os integrantes da Roda de Caxias se manifestaram de forma contrária.

Mestre Magal ${ }^{12}$, ao ser perguntado sobre porque a capoeira deixou os espaços públicos e foi para os espaços fechados, disse o seguinte:

Houve uma espécie de malta nas rodas de capoeira da Baixada Fluminense, pois estas rodas públicas se tornaram acirradas devido aos grupos e indivíduos de capoeira que se infiltravam nelas, promovendo vandalismo, rivalidades, resolução de "rinchas" e competições. Nesse sentido, essas rodas passaram a ser espaços de disputas entre os capoeiras, alguma delas de maneira bem violenta. (COSTA, 2018, p.89).

Foi com a profissionalização, processo de institucionalização, que a prática da capoeira vai, aos poucos, deixando os espaços públicos e ocupando os espaços privados das academias, escolas, centros culturais e igrejas. Existe hoje alguma roda de capoeira tradicional que acontece em determinados espaços públicos, todavia sua regularidade não é mais a mesma. Para Mestre Rui Charuto: "o ponto forte da capoeira eram as rodas de capoeira abertas pelas localidades da Baixada" (COSTA, 2018, p.90).

\footnotetext{
12 Júlio César Jugnático (Mestre Magal), atual coordenador das aulas de capoeira da Casa de Cultura da Baixada.
} 
Mestre Canela ${ }^{13}$ foi o fundador da roda de capoeira em um desses espaços em 1978, onde hoje é a sede da Casa da Cultura. Segundo ele:

No início era um imenso terreno baldio coberto de mato, a roda de capoeira conseguia atrair muitas crianças. A tradição da capoeira na Casa da Cultura é forte e se mantém até o momento. Eu conduzi o grupo até me afastar por problemas de saúde, hoje estou dedicado à família. (COSTA, 2018, p.90).

Foi na contramão dessa profissionalização da capoeira nos espaços privados que a Roda de Capoeira de Caxias se aproximou do estilo da capoeira Angola e se manteve nos espaços públicos, passando por etapas de preconceitos, perseguições e conflito pelo espaço com comerciantes, policiais e outras manifestações populares.

Essa relação entre preconceito e resistência aparece na fala de mestre Sampaio" ${ }^{14}$ : "Em grande parte, esta resistência se deve ao preconceito sobre as manifestações culturais de origem afro-brasileira e a capoeira está inserida nesse contexto. O preconceito sobre a capoeira historicamente foi reduzindo, mas continua presente" (COSTA, 2018, p.92).

Os capoeiristas foram historicamente vítimas de uma intensa perseguição, segundo entrevista de Mestre Portes ${ }^{15}$ (COSTA, 2018). Ele lembra que os capoeiristas, para receberem uma credencial (carteira) de vínculo à Associação de Capoeira Waldir Sales, tiveram que ser "fichados" na polícia. Já para Mestre Raimundo ${ }^{16}$, ainda existe um preconceito sobre a capoeira, porém em menor grau se comparado ao início: "reduziu muito o preconceito sobre ela, a ponto de já haver um pequeno reconhecimento do poder público sobre os praticantes da capoeira" (COSTA, 2018, p.92). Isso fez com que, segundo ele, os núcleos de capoeira na Baixada tivessem um aumento, saindo do "fundo do quintal", se tornaram mais técnicos e melhoraram no ponto de vista da formação dos alunos.

Boa parte dos integrantes originais da "Roda de Caxias" levaram a sua experiência, prática e memória para o mundo, ajudando a difundir a capoeira em outros paises. Esse fato é assim relatado:

\footnotetext{
${ }_{13}$ Jorge Inês de Souza (Mestre Canela) começou novo na capoeira, aos doze anos. Foi aprendiz do Mestre Josias da Silva e coordenou a roda de capoeira na Casa da Cultura da Baixada.

${ }^{14}$ Arlindo Ribeiro Sampaio (Mestre Sampaio) nasceu em janeiro de 1963 e foi formado pelo mestre Silas. Integra a Associação Desportiva Cultural Brasileira de Capoeiragem.

15 Jorge Porte (Mestre Portes) foi aluno do mestre Valdir Sales e iniciou na capoeira em 1972.

${ }^{16}$ Raimundo Silva Filho (Mestre Raimundo) nasceu em 1950, oriundo da cidade de Jequié-BA. Chegou ao Rio de Janeiro em 1954 e teve seu primeiro contato com a capoeira em 1958, tendo sido influenciado pelo seu mestre Josias da Silva.
} 
Na segunda metade da década de noventa, com a capoeira em plena difusão, percebe-se a construção de uma interface entre Duque de Caxias e o cenário internacional. Nesse sentido, destacamos Cobra Mansa, Jurandir, Marcão e Borracha nos Estados Unidos, Rogério na Alemanha e Pedrinho na Argentina e México. (MARQUES; FILHO, 2011, p.86).

Outros fatores importantes da "Roda de Caxias" são: (i) sua resistência a regras e formalização da institucionalização da capoeira, como hierarquia, uniforme, cordas, por exemplo; (ii) a ênfase na prática cultural e não na esportiva e (iii) a visibilidade da sua prática nos espaços públicos, ao invés dos espaços privados.

A Roda de Caxias, segundo os depoimentos, continua à margem do circuito de uma capoeira esportiva e parece não ter interesse em participar dela, talvez pelo fato de que a maioria dos freqüentadores está vinculada à capoeira Angola, mesmo que alguns deles não definam um estilo no interior da roda. O discurso da Capoeira Angola é que sua técnica corporal se baseia mais numa prática cultural do que esportiva - observemos aqui que o cultural significa pureza, raiz e se transforma num discurso identitário essencialista. O esportivo já é encarado como artificial e como ruptura total com as "tradições da verdadeira capoeira". (ALMEIDA; BARTHOLO; SOARES,2013, p.130).

Como vimos, a "Roda de Caxias" empreendeu táticas de defesa para permanecer nos espaços públicos e, por exemplo, ajudou a manter viva uma outra narrativa da capoeira: a presença nos espaços públicos, nas rodas tradicionais e, até, nos espaços privados, em que acontecem rodas públicas periódicas desses grupos.

\section{Considerações finais}

Este artigo buscou o diálogo com o campo de estudo da memória social, sua metodologia e alguns de seus autores, para pensar a capoeira enquanto objeto de investigação. A abordagem histórica em Walter Benjamin (1985) e Michel Foucault (1989) foi oportuna para abordar a capoeira no contexto da relação de poder e de dominação. Essa relação produziu rastros e vestígios que, segundo Jeanne Marie Gagnebin (2012), foram deixados pelos ausentes da história oficial e que podem ser vistos como outras possibilidades de interpretação de uma imagem imutável dos acontecimentos e das obras do passado. 
Essa abordagem histórica se juntou ao conceito de memória coletiva de Maurice Halbwachs (2006) e de outros pensadores da memória social, para trabalhar com a história oral dos mestres de capoeira da região da Baixada Fluminense. Foi nas entrevistas desses mestres que o "eu" revelou o coletivo (HALBWACHS, 2006), pois o depoimento de cada mestre revelou aspectos vivos das lembranças da capoeira na Baixada, construindo e deixando vir à tona pelas suas lembranças coletivas, nomes, localidades e vivências.

A capoeira no espaço da Baixada Fluminense, através da oralidade de seus mestres, deixa transparecer narrativas de seu passado e do seu presente, compondo novos elementos e visões para a compreensão da história da região em que vivem. Essas memórias reconstroem um contexto social de migração, resistência e estratégia de sobrevivência através das práticas culturais da capoeira.

Por fim, a memória social cria possibilidades de compor narrativas que podem revelar a diversidade da visão histórica, ajudando a compor narrativas diferentes. Ela também pode revirar e seguir os rastros de memória e lançar luz sobre comunidades, grupos socais e traços culturais que estão ausentes da história oficial. É nesses dois sentidos que a pesquisa sobre a capoeira na Baixada Fluminense tem sido realizada.

Espera-se que este trabalho de pesquisa possa suscitar novas investigações e contribuir para o campo de estudo da memória social.

\section{THE CAPOEIRA SOCIAL MEMORY: HISTORY AND NARRATIVES}

ABSTRACT: The theme proposed by this article is the social memory of capoeira and its presence in the Baixada Fluminense region -RJ, Brazil. Its objective is to understand the following issues: (i) the context of migration of capoeira to this region; (ii) the emergence of capoeira in Baixada Fluminense and; (iii) the places capoeira has occupied and has been occupying. The capoeira was present in important historical moments of the country. However, in the relationship of power between the dominant and the dominated, it was persecuted and prohibited. This attempt to social exclusion left traces and vestiges which, through academic, archivist and ethnographic research, have been building the memory of capoeira in different locations. This is the case of the presence of capoeira in Baixada Fluminense region, which, through the memory of its masters, has been gaining visibility.

KEYWORDS: Social Memory. Capoeira. Baixada Fluminense. 


\section{LA MEMORIA SOCIAL DE LA CAPOEIRA: HISTORIA Y NARRACIONES}

RESUMEN: El tema propuesto por este artículo es la memoria social de la capoeira y su presencia en la región de la Baixada Fluminense-RJ. Su objetivo es comprender las siguientes cuestiones: i) el contexto de la migración de la capoeira a esta región; ii) el surgimiento de la capoeira en la Baixada Fluminense y; iii) los lugares que la capoeira ha ocupado y ha estado ocupando. Para esto considera que la capoeira estuvo presente en importantes momentos históricos del país, sin embargo, en la relación de poder entre los dominantes y los dominados, fue perseguida y prohibida. Este intento de exclusión social ha dejado huellas y rastros que, a través de investigaciones académicas, archivisticas y etnográficas, han ido construyendo la memoria de la capoeira en varios lugares. Este es el caso de la presencia de la Capoeira en la región de la Baixada Fluminense-RJ, que, a través de la memoria de sus maestros, está ganando visibilidad.

PALABRAS CLAVE: Memoria Social. Capoeira. Baixada Fluminense.

\section{REFERÊNCIAS}

ABREU, Frede; CASTRO, Maurício Barros de (org.). Capoeira. Rio de Janeiro: Beco do Azougue, 2009.

ALMEIDA, Marcelo N.; BARTHOLO, Tiago L.; SOARES, Antonio J. Uma roda de rua: notas etnográficas da roda de capoeira de Caxias. Revista Portuguesa de Ciências do Desporto. 7 (1), p.124-133, 2013.

BARRENECHEA, Miguel Angel. Nietzsche e a genealogia a da memória social. In: GONDAR, J.; DODEBEI, V. (Org.). O que é memória social? Rio de Janeiro: Universidade Federal do Estado do Rio de Janeiro, 2005.

BENJAMIN, Walter. Magia e técnica, arte e política: ensaio sobre literatura e história da cultura. Rio de Janeiro: Brasiliense, v. 1, 1985.

BRASIL. Ministério da Cultura. Instituto do Patrimônio Histórico e Artístico Nacional. Inventário para registro e salvaguarda da capoeira como patrimônio cultural do Brasil. Brasília: MEC, 2007. 
BRASIL. DECRETO No 847, DE 11 DE OUTUBRO DE 1890. Câmara dos Deputados. Disponível em: https:/www2.camara.leg.br/legin/fed/decret/1824-1899/decreto-847-11outubro-1890-503086-publicacaooriginal-1-pe.html. Acesso em: 17 set. 2020.

CORDEIRO, Veridiana Domingos. Os diferentes enfoques da memória. Revista Sociologia. São Paulo, Ano V, Edição. 55, p. 24-29, nov./dez. 2006.

COSTA, Marcelo Cardoso da. O berimbau na cidade: história, resistência e memória social da capoeira. In: FELIPE, D. A.; OLIVEIRA, O. F.; ESCOBAR, G.V. (org.). Patrimônio e cultural afro-brasileira: memória, identidade e reconhecimento. São Paulo: Ribeirão Gráfica e Editora, 2018, p.78-95.

COSTA, Marcelo Cardoso da; RANGEL, André S. Capoeira: resistência da cultura afrobrasileira na Baixada Fluminense. Revista Casa da Cultura. Rio de Janeiro: ONG Casa da Cultura, set. 2010.

FOUCAULT, Michael. O sujeito e o poder. In: DREYFUS, H. L.; RABINIV, P. (org.). Michel Foucault. Uma trajetória filosófica: para além do estruturalismo e da hermenêutica. Rio de Janeiro: Forense Universitária, p.273-295, 1995.

FOUCAULT, Michel. Microfísica do poder. Rio de Janeiro: Graal, 1989.

GAGNEBIN, Jeanne Marie. Apagar os rastros, recolher os restos. In: SEDLMAYER, S; GINZBURG, J. (org.). Walter Benjamin. Rastro, aura e História. Belo Horizonte: EdUFMG, p.27-38, 2012.

GONDAR, Jô. Cinco proposições sobre Memória Social. In: DODEBEI, Vera, FARIAS, Francisco R.de; GONDAR, Jô (Org.) Por que memória social? 1. ed. Rio de Janeiro: Híbrida, 2016. Revista Morpheus: estudos interdisciplinares em Memória Social: edição especial, ISSN 1676-2924; v. 9, n. 15.

GONDAR, Jô; DODEBEI, Vera (org.). O que é memória social? Rio de Janeiro: Universidade Federal do Estado do Rio de Janeiro, 2005.

HALBWACHS, Maurice. Memória coletiva. São Paulo: Centauro, 2006.

HOLlOWAY, Thomas H. Polícia no Rio de Janeiro: repressão e resistência numa cidade do século XIX. Rio de Janeiro: Fundação Getúlio Vargas, 1997.

KARASCH, Mary C. A vida dos escravos no Rio de Janeiro (1808-1850). São Paulo: Companhia das Letras, 2000. 
MARQUES, A. S.; FILHO, G. C. A trajetória da capoeira em Duque de Caxias. Revista Pilares da História, Duque de Caxias, ano 10, edição especial, p.79-90, nov. 2011.

OLICK, Jeffrey K.; VINITZKY-SEROUSSI, Vered; LEVY, Daniel. The collectie memory reader. New York: Oxford University Press, 2011.

OLIVEIRA, Josivaldo Pires de; LEAL, Luiz Augusto Pinheiro. Capoeira, identidade e gênero: ensaios sobre a história social da capoeira no Brasil. Salvador: EDUFBA, 2009.

POLLAK, Michael. A gestão do indizível. Revista do Instituto Cultural Judaico Marc Chagall. V. 2, n. 1, p.9-49, 2010.

RIO DE JANEIRO. Estado do Rio de Janeiro, Maricá e Desenvolvimento Econômico. Prefeitura de Maricá, 2018. Disponível em: https:/www.marica.rj.gov.br/wpcontent/uploads/2018/12/Conselho-Desenv-Econ\%C3\%B4mico-06122018.pdf. Acesso em 15 set. 2020.

RUFINO, Luiz. A capoeira como filosofia da ancestralidade. Revista Íbamò. Rio de Janeiro, V. 1, p.125-130, nov. 2018.

RUFINO, Luiz.; PEÇANHA, Cinézio Feliciano; OLIVEIRA, Eduardo. Pensamento diaspórico e o "ser" em ginga: deslocamentos para uma filosofia da capoeira. Revista de Humanidades e Letras, Ceará, v. 4, n. 2, p.73-84, 2018. Disponível em:

http://www.capoeirahumanidadeseletras.com.br/ojs-2.4.5/index.php/capoeira/article/view/124. Acesso em: 15 set. 2020.

SARLO, Beatriz. Tempo passado: cultura da memória e guinada subjetiva. São Paulo:

Companhia das Letras, 2007.

SILVA, Tomaz Tadeu. Identidade e diferença: a perspectiva dos estudos culturais. Petrópolis. Vozes, 2003.

SOARES, Carlos Eugênio Libâneo. A Capoeira Escrava e outras tradições rebeldes no Rio de Janeiro (1808 - 1850). Campinas: Editora da UNICAMP, 2004.

SOARES, Carlos Eugênio Libâneo. A negregada instituição: os capoeiras na corte imperial 1850-1890. 1. ed. Rio de Janeiro: Access Editora, 1999. 


\section{Entrevistas}

DE PAULA, W. S. (Mestre Warle). A capoeira na Baixada Fluminense. Entrevistadores: André Rangel e Marcelo Cardoso da Costa. Revista Casa da Cultura, São João de Meriti, maio 2010 .

JUGNÁTICO, J. C. (Mestre Magal). A capoeira na Baixada Fluminense. Entrevistadores: André Rangel e Marcelo Cardoso da Costa. Revista Casa da Cultura, São João de Meriti, maio 2010 e out. 2013.

MONTANHEIRO, R. (Mestre Rui Charuto). A capoeira na Baixada Fluminense.

Entrevistadores: André Rangel e Marcelo Cardoso da Costa. Revista Casa da Cultura, São João de Meriti, jun. 2010.

PORTE, J. (Mestre Portes). A capoeira na Baixada Fluminense. Entrevistadores: André Rangel e Marcelo Cardoso da Costa. Revista Casa da Cultura, São João de Meriti, maio 2010.

SAMPAIO, A. R. (Mestre Sampaio). A capoeira na Baixada Fluminense. Entrevistadores: André Rangel e Marcelo Cardoso da Costa. Revista Casa da Cultura, São João de Meriti, mar. 2010.

SANTOS, R. P. (Mestre Reginaldo Pimentel). A capoeira na Baixada Fluminense.

Entrevistadores: André Rangel e Marcelo Cardoso da Costa. Revista Casa da Cultura, São João de Meriti, jun. 2010.

SILVA FILHO, R. (Mestre Raimundo). A capoeira na Baixada Fluminense. Entrevistadores: André Rangel e Marcelo Cardoso da Costa. Revista Casa da Cultura, São João de Meriti, jun. 2010 .

SOUZA, J. I, (Mestre Canela). A capoeira na Baixada Fluminense. Entrevistadores: André Rangel e Marcelo Cardoso da Costa. Revista Casa da Cultura, São João de Meriti, jun. 2010.

SOUZA, L. T. (Mestre Levi). A capoeira na Baixada Fluminense. Entrevistadores: André Rangel e Marcelo Cardoso da Costa. Revista Casa da Cultura, São João de Meriti, mar. 2010.

Recebido em 19/11/2019.

Aprovado em 04/06/2020. 